DOI: $10.36910 / 6775-2524-0560-2019-36-15$

УДК 004.932

Поляченко А. I.

Київський національний університет імені Тараса Шевченка

\title{
ЗГОРТКОВА НЕЙРОННА МЕРЕЖА ДЛЯ КЛАСИФІКАЦІЇ ТОМОГРАФІЧНИХ І РЕНТГЕНІВСЬКИХ ЗНІМКІВ В СИСТЕМІ РОЗПІЗНАВАННЯ
}

\begin{abstract}
Поляченко А. І. Згорткова нейронна мережа для класифікації томографічних і рентгенівських знімків в системі розпізнавання. У роботі запропоновано та побудовано систему розпізнавання томографічних і рентгенівських знімків для пошуку і локалізації патологій. Дана система включає блоки: введення інформації про пацієнта, обробки медичних зображень, для встановлення висновку, для класифікації виявлених патологій, базу даних, підготовки звіту. У статті приділено увагу особливостям розробки згорткової нейронної мережі для класифікації томографічних i рентгенівських знімків в системі розпізнавання, призначеної для пошуку і локалізації патологій. В результаті, було запропоновано згорткову нейронну мережу для класифікації томографічних і рентгенівських знімків в запропонованій системі розпізнавання, призначеної для пошуку і локалізації патологій.
\end{abstract}

Ключові слова: система розпізнавання, згорткова нейронна мережа, томографічні та рентгенівські знімки, пошук i локалізація патологій, медичні зображення.

Поляченко А. И. Сверточная нейронная сеть для классификации томографических и рентгеновских снимков в системе распознавания. В работе предложена и построена система распознавания томографических и рентгеновских снимков для поиска и локализации патологий. Данная система включает блоки: ввод информации о пациенте, обработки медицинских изображений, для установления выводу, для классификации выявленных патологий, базу данных, подготовки отчета. В статье уделено внимание особности разработки сверточной нейронной сети для классификации томографических и рентгенских снимков в системе распознавания, предназначенной для поиска и локализации патологий. В результате, было предложено сверточную нейронную сеть для классификации томографических и рентгеновских снимков в предложенной системе распознавания, предназначенной для поиска и локализации патологий.

Ключевые слова: система распознавания, сверточная нейронная сеть, томографические и рентгеновские снимки, поиск и локализация патологий, медицинские изображения.

Poliachenko A. I. Convolutional neural network for the classification of tomographic and X-ray images in the recognition system. In this work, a tomographic and X-ray recognition system was proposed and constructed for the search and localization of pathologies. This system includes the following blocks: patient information input, medical image processing, output, classification of detected pathologies, database, report preparation. The article focuses on the peculiarities of the development of a convolutional neural network for the classification of tomographic and X-ray images in a recognition system designed for the search and localization of pathologies. As a result, a convolutional neural network was proposed for the classification of tomographic and X-ray images in the developed recognition system designed to search for and locate pathologies.

Key words: recognition system, convolutional neural network, tomography and X-ray images, pathology search and localization, medical images.

1. Постановка проблеми. Сучасна медицина залежить від технічних досягнень у сфері медичного приладобудування та розвитку медичного програмного забезпечення. Однією 3 найважливіших задач, що постає перед лікарями, є визначення точних меж пухлин та інших аномальних утворень у тканинах організму людини. Для обстеження пацієнта, як правило, використовуються методи комп'ютерної та магнітно-резонансної томографії (КТ та МРТ відповідно). Обидва методи дозволяють проводити пошарове вивчення внутрішньої будови органічних структур без їх фізичного пошкодження (якщо не розглядати можливі побічні ефекти у результаті опромінення чи тривалого знаходження у потужному магнітному полі). Результатом обстеження $\epsilon$ серія знімків, що відповідають обраним площинам сканування. Шляхом виконання досить нетривіальних обчислень, програмне забезпечення томографічних робочих станцій відтворюе структурне зображення об'єкта сканування на основі даних про рентгенівську щільність (КТ) чи відклик атомів водню (МРТ). На основі отриманих знімків лікар візуально визначає наявність аномальних утворень та їх межі. Проблема полягає у тому, що наявність пухлин досить просто визначити візуально у силу їх характерних структурних особливостей, у той час як визначення точних меж між здоровими та ураженими тканинами є дуже складною задачею, яку практично неможливо вирішити без виконання додаткових замірів та розрахунків. Складність цієї задачі $\epsilon$ наслідком того, що здорові та уражені тканини на знімках КТ та МРТ можуть виглядати практично однаково, у сенсі, наприклад, кольору відповідних областей, що, у свою чергу, унеможливлює використання методів візуального аналізу зображення для виявлення меж між вказаними областями. Тому виникає необхідність у побудові системи розпізнавання томографічних і рентгенівських знімків для пошуку і локалізації патологій 3 класифікацією таких знімків. 
2. Аналіз останніх досліджень і публікацій. Аналіз медичних зображень полягає у виборі алгоритму, найбільш підходящого для його сегментації $[1,4,5,8,10,11,13]$. Фактично таке завдання стоїть, перед розробниками програмних засобів для КТ і МРТ-обладнання, а не перед лікарямиклініцистами, які використовують методи променевої діагностики. При виборі алгоритму доводиться враховувати як властивості конкретного медичного зображення, так і особливості певного алгоритму сегментації [15-17].

Автори роботи [4] класифікують методи сегментації в залежності від властивостей, на основі яких вони виконуються (розривність або схожість низькорівневих ознак); стратегій обробки зображення (послідовна або паралельна); типу зображення (кольорове або півтонове); наявності в використовуваному методі вбудованого (внутрішнього) критерію для перевірки якості сегментації. У роботах $[9,14]$ методи сегментації поділяються на три класи в залежності від того, що лежить в їх основі: край, область або пікселі. Класифікація методів сегментації в залежності від застосовуваного математичного апарату розглянута в роботі [2]. За цією ознакою розрізняють порогову сегментацію; морфологічну сегментацію і метод нарощування областей. У деяких роботах [3, 7], класифікація методів сегментації розглядається з точки зору участі оператора в процесі сегментації: інтерактивні, автоматичні, напівавтоматичні. Класифікувати методи сегментації, які найбільш часто використовують в завданнях обробки медичних зображень можна наступним чином: порогові методи; методи виявлення країв; методи виділення областей; метод морфологічного водорозділу; методи, засновані на атласах; методи кластеризації; штучні нейронні мережі. Для оцінки ефективності застосування того чи іншого методу використовуються, як правило, такі показники [6]: чутливість; специфічність; точність. Практика показує, що один і той же метод може показати гарні результати на певних медичних зображеннях, а на інших зображеннях того ж типу може бути неефективним [12].

Мета роботи - розробка згорткової нейронної мережі для класифікації томографічних і рентгенівських знімків в системі розпізнавання, призначеної для пошуку і локалізації патологій.

Виклад матеріалу дослідження. Для пошуку i локалізації аномалій на томографічних i рентгенівських знімках пропонується система, яка складатиметься з блоків, приведених на рис. 1. У приведеній функціональній структурі пропонуємої системи початковим етапом $\epsilon$ отримання томографічних чи рентгенівських знімків, які, далі, поступають до блоків введення інформації про пацієнта і обробки медичних зображень. Інформація про пацієнта в результаті введення потрапляє до бази даних разом із томографічними чи рентгенівськими знімками. Блок обробки медичних зображень із внутрішніми зв'язками має наступну структуру (рис. 2). Приведена структура блоку обробки медичних зображень пропонуємої системи включає 4 підсистеми, які охоплюють автоматичну обробку томографічних чи рентгенівських знімків, а також обробку в ручному режимі лікарем-діагностом.

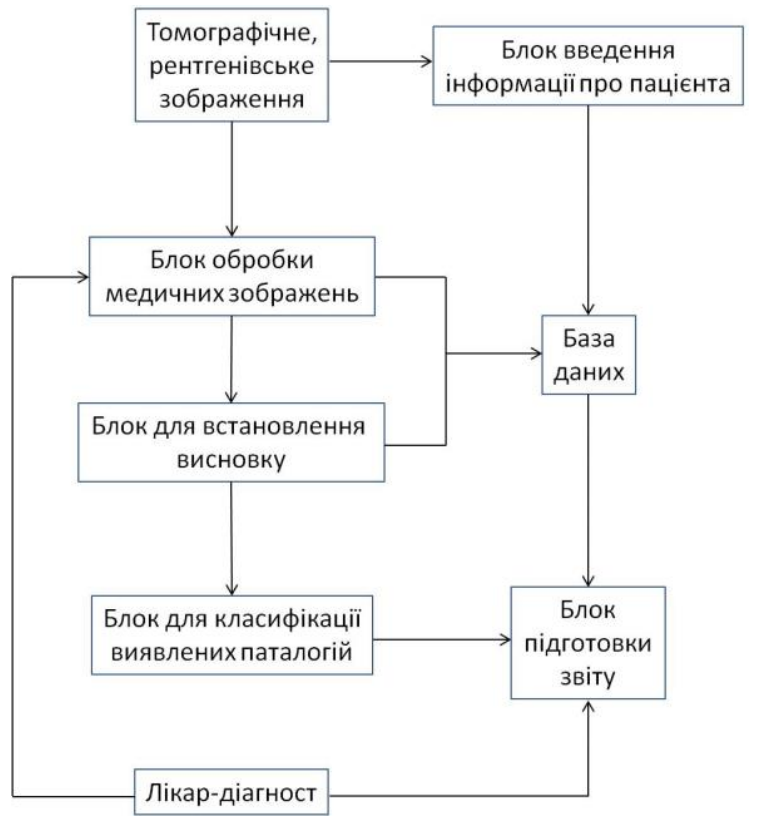

(C) Поляченко А. I. 
Рис. 1. Загальний вигляд функціональної структури пропонуємої системи розпізнавання томографічних і рентгенівських знімків для пошуку і локалізації патологій

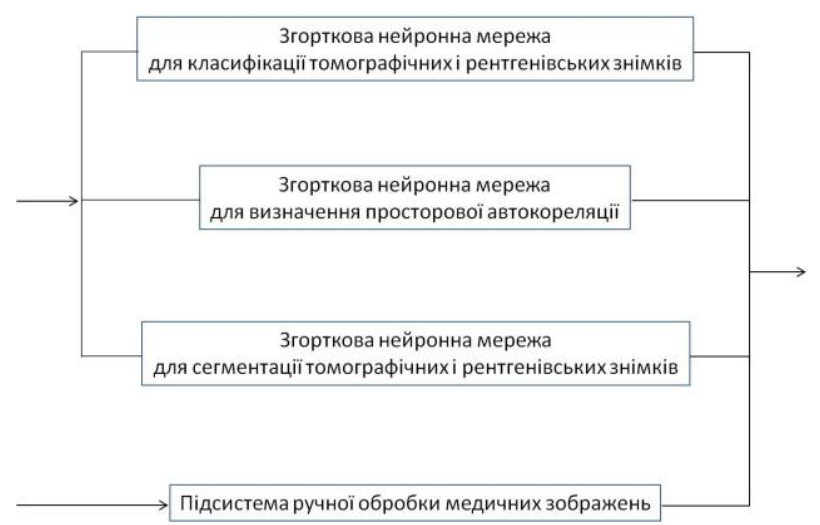

Рис. 2. Структура блоку обробки медичних зображень

У даній статті, приведено особливості розробки згорткової нейронної мережі для класифікації медичних знімків без використання відкритого джерела в системі розпізнавання, призначеної для пошуку і локалізації патологій.

Для встановлення патології на КТ і МРТ знімках можуть бути застосовані згорткові нейронні мережі, які дозволять виконати їх класифікацію та отримати текстовий висновок.

Ідея згорткової нейронної мережі полягає в чергуванні згорткових шарів (convolutionlayers) i субдискретних шарів (subsamplinglayers, шарів підвибірки). Структура згорткової нейронної мережі односпрямована (без зворотних зв'язків), принципово багатошарова. Для навчання використовуються стандартні методи, найчастіше метод зворотного поширення помилки. Функція активації нейронів (передавальна функція) - будь-яка, за вибором дослідника. У згорткових шарах, приховані нейрони замінюються згортковими фільтрами. Замість підбору ваг для нейронів, необхідно вирішити завдання підбору ваг для сімейства фільтрів. Згорткові шари впорядковують нейрони в тривимірному режимі 3 використанням висоти, ширини і глибини для оброблюваного сигналу.

Розглянемо особливості побудови згорткової нейронної мережі для класифікації медичних знімків без використання відкритого джерела в системі розпізнавання, призначеної для пошуку і локалізації патологій.

Робота нейронної мережі пов'язана з ініціалізацією ваг $w_{i j}^{(l)}$, які позначають вагу на шляху від $i$-го нейрона в $(l-1)$-му шарі до $j$-го нейрону в $l$-му шарі.

На першому етапі береться одна послідовність даних, 3 встановленням вхідних значень кожного нейрона $y_{i}^{(0)}$ в 0-му (вхідному) шарі 3 відміткою у вихідному шарі. Далі обчислюється сумарний чистий вхідний сигнал від попереднього шару до кожного прихованого нейронного шару $x_{j}^{(l)}$ у наступному шарі і обчислюється загальний вхідний сигнал, 3 використанням функції активації для виходу в наступному шарі $y_{j}^{(l)}$, потім повторюється процес з нейронами вихідного шару. Це може бути записано в наступному вигляді:

$$
\begin{aligned}
& X(l)=Y^{(l-1)} W^{(l-1)}, \\
& W^{(l-1)} \in R(d(l-1) \times d(l)) \\
& Y^{(l)}=\sigma\left(X^{(l)}\right), X^{(l)} \text { i } Y^{(l)} \in R(d(l) \times 1)
\end{aligned}
$$

де $d(l)$ - кількість нейронів у l-му шарі.

Далі здійснюється зворотне поширення помилки у вигляді:

$$
W^{(l)}=W^{(n)}-\eta d W^{(l)} \text {. }
$$


Виконується обчислення матриці градієнтів $d W$ за вагами від другого останнього шару до останнього вихідного шару $(l=n)$. Помилку можна обчислити за виразом:

$$
E=\frac{1}{2}\left(\text { label } l_{j}^{(n)}-y_{j}^{(n)}\right)^{2},
$$

а значення градієнта кожної ваги між останнім шаром і його попередніми шаром складе:

$$
\begin{gathered}
\delta^{(n)}=-\left(E-Y^{(n)}\right) \sigma^{n}\left(X^{(n)}\right), \\
\delta(n) \in R(d(n) \times 1) \\
d W^{(n-1)}=\left(Y^{(n-1)}\right)^{T} \delta^{(n)} .
\end{gathered}
$$

Проводиться обчислення градієнта в попередніх шарах $(L=n-1)$;

$$
\begin{array}{r}
\delta(l)=W^{(l)}\left(\delta^{(l+1)}\right) ; \\
d W^{(l-1)}=\left(Y^{(l-1)}\right)^{T} \delta^{(l)} .
\end{array}
$$

Процес повторюється до тих пір, поки всі ваги в нейронній мережі не будуть оновлені. ітерації.

Повинен існувати зворотний зв'язок для поновлення ваг, який допомагає досягти певної

Робота згорткової нейронної мережі заснована на базових нейронних мережах, які описані вище, а алгоритм складається з двох основних процесів: згортки і дискретизації, які відбуваються на згортальних шарах і максимальних рівнях пулу.

В процесі згортки кожен нейрон отримує вхідні дані у вигляді матриці $n \times n$ попереднього шару, яке є локальним рецептивним полем, що можна записати як:

$$
x_{i, j}^{(l)}=\sigma\left(b+\sum_{r=0}^{n} \sum_{c=0}^{n} w_{r_{i}, c} x_{i+r_{i} j+c}^{(l-1)}\right) .
$$

Кожному локальному рецептивному полю відповідають однакові ваги $w_{r_{i} c}$ і зміщення $b$, які визначаються з рівняння (6), що наведене вище, параметри якого можна розглядати як навчальний фільтр або ядро $F$.

У процесі згортки відбувається дія згортки медичного зображення, а згортковий шар $\epsilon$ результатом виведення попереднього шару. Даний процес представимо на рис. 3 .

В процесі дискретизації можливе об'єднання наступного шару після кожного згорткового шару. У результаті, дискретизація відбувається між згортковим шаром і шаром об’єднання.

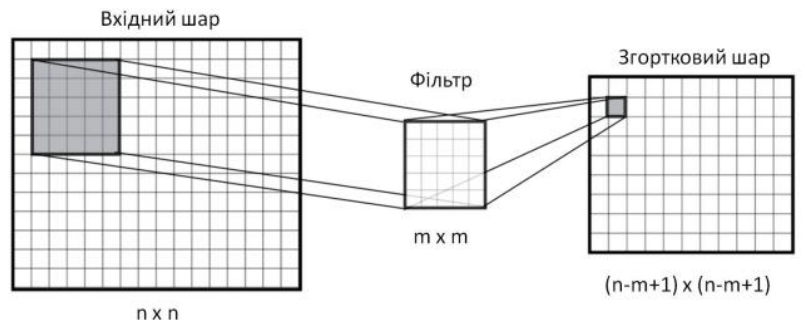

Рис. 3. Процес в шарах згорткової нейронної мережі

Шар пулу згорткової нейронної мережі відбирає маленькі прямокутні блоки зі згорткового шару і опрацьовує його. У даній роботі пропонується прийняти максимум блоку в якості одного виводу в шар пулу. Даний процес представимо на рис. 4. 


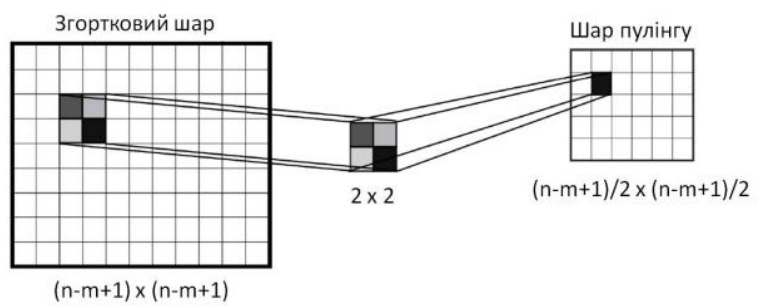

Рис. 4. Процес відбору прямокутних блоків зі загорткового шару згорткової нейронної мережі шаром пулу

Оскільки в існуючих областях медичних зображень прослідковується мало зв'язків, то використання згорткової нейронної мережі є доречним і їх набагато легше навчати, ніж звичайні нейромережі.

У вигляді активації виходу нейронів, застосовуються стандартні функції:

$y(x)=(1+e-x)-1$,

або

$y(x)=\tanh (x)$,

де $x$ - вхідні значення.

Існує проблема зникаючого градієнту, яка виникає, коли одиниці вищого шару майже насичені при -1 або 1, у результаті чого нижні шари згорткової нейронної мережі мають градієнти рівні, практично 0. Такі зникаючі градієнти викликають повільну збіжність оптимізації, а в деяких випадках остаточно навчена згорткова нейронна мережа показує погані результати з новою вибіркою зображень.

Таке може відбуватися при використанні вищезгаданих сигмовидної функції або функції гіперболічного тангенса. Тому для виключення проблеми зникаючого градієнта будемо використовувати функцію активації ReLU у вигляді:

$$
y=\max 0, \quad b+\sum_{i=1}^{k} x_{i} w_{i} .
$$

Для регуляції перенавчання згорткової нейронної мережі під час тренування випадаючі нейрони не беруть участі в прямому і зворотному поширенні. Випадання можна розглядати як дискретизацію нейронної мережі в межах згорткової нейронної мережі з оновленням параметрів на основі вхідних даних. При цьому для випадаючого шару забезпечується постійне його включення між повністю пов'язаними шарами. В шарі випадання вибір одиниць для випадання є випадковим i може бути прийнятий із значенням фіксованою ймовірністю, що дорівнює 0,5 .

Оскільки досліджуються медичні зображення 512 на 512 пікселів у форматі DICOM, то вхідний шар згорткової нейронної мережі буде містити 262144 (512х512) нейронів (рис. 5). 


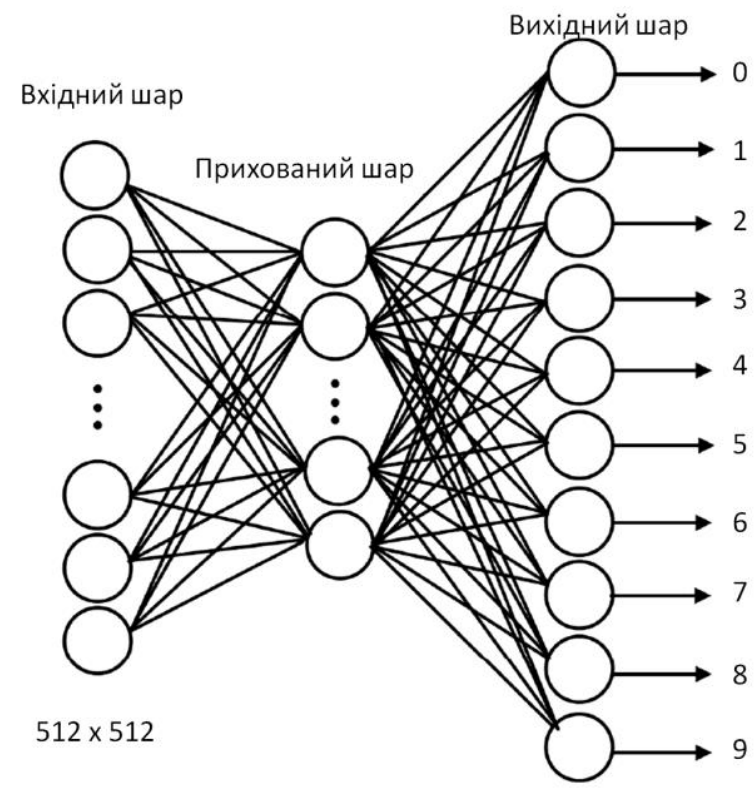

Рис. 5. Загальний вигляд шарів згорткової нейронної мережі

У згортковій нейронній мережі другий рівень $\epsilon$ прихованим, і цей шар позначимо як $n$ для визначення оптимальних даних за значенням цього прихованого шару.

На рис. 5, наведений приклад ілюструє невеликий прихований шар, що містить всього $n=30$ нейронів. Вихідний шар мережі містить 10 нейронів, які позначають 10 типів різних медичних зображень. Нумерація вихідних нейронів від 0 до 9 є символічною. У результаті для прогнозування повинен бути обраний нейрон з найвищим значенням активації.

Висновки. У роботі запропоновано та побудовано систему розпізнавання томографічних $\mathrm{i}$ рентгенівських знімків для пошуку і локалізації патологій. Дана система включає блоки: введення інформації про пацієнта, обробки медичних зображень, для встановлення висновку, для класифікації виявлених патологій, базу даних, підготовки звіту. У статті приділено увагу особливостям розробки згорткової нейронної мережі для класифікації томографічних і рентгенівських знімків в системі розпізнавання, призначеної для пошуку і локалізації патологій. В результаті, було побудовано згорткову нейронну мережу для класифікації томографічних $\mathrm{i}$ рентгенівських знімків в запропонованій системі розпізнавання, призначеної для пошуку і локалізації патологій.

\section{Список бібліографічних посилань}

1. Брумштейн Ю. М. Системный анализ направлений и особенностей информатизации сферы здравоохранения России. Прикаспийский журнал: управление и высокие технологии. 2013. № 4. С. 73-86.

2. Дороничева А. В. Методы распознавания медицинских изображений для задач компьютерной автоматизированной диагностики. Современные проблемы науки и образования. 2014. № 4. Режим доступа: www.science-education.ru/11814414.

3. Жук С. В. Обзор современных методов сегментации растровых изображений. Известия волгоградского государственного технического университета. 2009. № 6. С. 115-118.

4. Поршнев С. В. Универсальная классификация алгоритмов сегментации изображений. Журнал научных публикаций аспирантов и докторантов. 2008. № 3. С. 163-172.

5. Anam M. An Efficient Brain Tumor Detection Algorithm Using Watershed \& Thresholding Based Segmentation. Image, Graphics and Signal Processing. 2012. Vol. 10. Pp. 34-39.

6. Bansal S. Performance analysis of color based region split and merge and otsu's thresholding techniques for brain tumor extraction. International Journal of Engineering Research and Applications. 2013. Vol. 3, issue 4. Pp. 1640-1643.

7. Hakeem A. A. A new approach to image segmentation for brain tumor detection using pillar k-means algorithm. International Journal of Advanced Research in Computer and Communication Engineering. 2013. Vol. 2, issue 3. Pp. 1429-1436.

8. Hough P. V.C. Method and means for recognizing complex patterns .U.S. Patent 3,069,654. -December 18, 1962.

9. Kharrat A. Detection of brain tumor in medical images. International Conference on Signals, Circuits and Systems. 2009. Pp. 1-6.

10. Logeswari T. An improved implementation of brain tumor detection using segmentation based on hierarchical self organizing map. International Journal of Computer Theory and Engineering. 2010. Vol. 2, no. 4, pp. 1793-8201.

11. Marr D. Proceedings of the Royal Society of London. Series B, Biological Sciences. Vol. 207, no. 1167. Pp. 187-217.

12. Neeraj Sharma Automated medical image segmentation techniques. Journal of medical physics. 2010. No. 35. Pp. 3-14. 
13. Prewitt J. M. S. Object enhancement and extraction, picture processing and psychopictorics. NY : Academic Pres, 1970. Pp. $75-$ 149.

14. Rakesh M. Image segmentation and detection of tumor objects in MR brain images using fuzzy C-means (FCM) algorithm. International Journal of Engineering Research and Applications. 2012. No. 2, issue 3. Pp. 2088-2094.

15. Roberts L. G. Machine perception of three-dimensional solids. Optical and Electro-Optical Information Processing. MIT Pres, 1965. Pp. 159-197.

16. Robinson G. S. Edge detection by compass gradient masks. Computer Graphics and Image Processing. 1977. Vol. 6, no. 5. Pp. 492-502.

17. Sobel I. E. Camera models and machine perception, PHD dissertation. Stanford University, 1970. 303 p. 